The passage from the second group to the third brings us to those bodies which are increasing their temperature, in which radiation and fluting absorption have given place to line absorption.

At present the observations a.Iready accumulated have not been discussed in such a way as to enable us to state very definitely the exact retreat of the absorption, by which I mean the exact order in which the absorption lines fade out from the first members to the last in the group. We know generally that the earlier species will contain the line absorption of those substances of which we get a paramount fluting absorption in the prior group. We also know generally that the absorption of hydrogen will increase while the other diminishes.

The next group, the fourth, brings us to the stage of highest temperature, to stars like $a$ Lyræ; and the division between this group and the prior one must be more or less arbitrary, and cannot at present be defined. One thing, however, is quite clear, that no celestial body without all the ultra-violet lines of hydrogen discovered by Dr. Huggins can claim to belong to it.

We have now arrived at the culminating point of temperature, and now pass to the descending arm of the curve of temperature. The fifth group, therefore, will contain those bodies in which the hydrogen lines begin to decrease in intensity, and other absorptions to take place in consequence of reduction of temperature.

One of the most interesting problems of the future will be to watch what happens in bodies along the descending scale, as compared with what happens to the bodies in Group III. on the ascending one. But it seems fair to assume that physical and chemical combinations will now have an opportunity of taking place, thereby changing the constituents of the atmosphere; that with every decrease of temperature an increase in the absorption lines may be expected, but it will be unlikely that the last species in this group will resemble the first one in Group III.

The next group, the sixth, is Secchi's type IV. and Vogel's Class III.b, its distinct characteristics being the absorption flutings of carbon. The species of which it will ultimately be composed are already apparently shadowed forth in the map which accom panies Dunér's volume, and they will evidently be subsequently differentiated by the gradual addition of other absorptions to that of carbon, while at the same time the absorption of carbon gets less and less distinct.

To sum up, then, the classification I propose consists of the following groups :-

Group I.-Radiation lines and flutings predominant. Absorp. tion beginning in the last species.

GRouP II.-Mixed radiation and absorption predominant.

Group III.-Line absorption predominant, with increasing temperature. The various species will be marked by increasing simplicity of spectrum.

GROUP IV.--Simplest line absorption predominant.

GRoup V.-Line absorption predominant, with decreasing temperature. The various species will be marked by decreasing complexity of spectrum.

Group VI.-Carbon absorption predominant.

Group VII. - Extinction of luminosity.

It will be seen from the above grouping that there are several fundamental departures from previous classifications, especially that of Vogel.

The presence of the bright flutings of carbon associated with dark metallic flutings in the second group, and the presence of only absorbing carbon in the sixth, appears to me a matter of fundamental importance, and to entirely invalidate the view that both groups (the equivalents of III. $a$ and III. $b$ of Vogel) are produced from the same mass of matter on cooling.

This point has already been dwelt upon by Pechüle.
Another point of considerable variation is the separation of stars with small absorption into such widely different groups as the first and fourth, whereas Vogel classifies them together on the ground of the small absorption in the visible part of the spectrum. But that this classification is unsound is demonstrated by the fact that in these stars, such as $\gamma$ Cassiopeiæ and $\beta$ Lyræ, we have intense variability. We have bright hydrogen lines instead of inordinately thick dark ones; and on other grounds, which I shall take a subsequent opportunity of enlarging upon, it is clear that the physical conditions of these bodies must be as different as they pretty well can be.

It will be seen also that, with our present knowledge, it is very difficult to separate those stars the grouping of which is determined by line absorption into the Groups III. and V., for the reason that so far, seeing that only one line of temperature, and that a descending one, has been considered, no efforts have been made to establish the necessary criteria. I made this point in the paper to which I have already referred in connection with the provisional curve, and for purposes of completeness $I$ introduce here the chief part of what I wrote on that occasion.

(To be continued.)

\section{THE HITTITES, WITH SPECIAL REFERENCE TO VERY RECENT DISCOVERIES. ${ }^{1}$}

$\mathrm{V}$.

SOME months ago the Rev. Greville J. Chester brought to this country a quadrangular hæmatite seal found near Tarsus. Though this seal shows, in certain particulars, some analogy with the Yuzgât seal, yet it gives little or no additional aid in the decipherment of the inscriptions. It presents, nevertheless, features of very great interest. Prof. Sayce scarcely goes beyond the merits of the seal when he says that it possesses a "unique and splendid character; nothing like it has ever before been brought to the notice of European scholars." 2 The seal is engraved not only on the base ( 1$)$, but also on the four sides, while opposite the base the stone was so cut as to serve the purpose of a handle. On four out of the five engraved faces are to be seen two figures-one seated and one standing. These may be supposed to represent men or deities, or possibly, in some cases, ideal personages. At first sight it may seem difficult to discern any general aim or connected purpose in the curious figures depicted. On more attentive examination, however, there is seen to be exhibited a pervading principle of tri-unity, especially as exemplified in the triangle and the trident. Moreover, while on three faces of the $\operatorname{seal}(I, 2,5)$ there are figures with the "pig-tail" (an appendage which suggests a connection with the Hittites), it appears tolerably evident that the engraver of the seal intended to represent the personages with this appendage as destitute of the valuable knowledge and power connected with the mysterious three-in-oneness of the triangle and the trident. This is entirely in accordance with the position that the wearers of the pig-tail were still regarded as aliens and intruders when the seal was engraved.

On the base (I), a figure standing or advancing holds in the left hand a trident-like object, which is probably to be understood as a plant; though, like the curious symbols on the Boghaz-Keui bas-relief (supra, pp. 5I3, 5I4), it must be somewhat idealized. Certainly, it would seem

I Based on Lectures delivered by Mr. Thomas Tyler at the British Museum in January 1888 . Continued from p. 593

2 Archaological fournal, December 1887. Prof. Sayce's paper is accom. panied by an autotype representation of the seal. I may here mention, also, that impressions of this seal, as also of the Yuzgât seal and the seal of Tarkutimme, may be obtained at a small cost from Mr. A. Ready, of the British Museum. 
difficult or impossible to identify it with any known vegetable production. And it would be equally difficult to determine what is the plant held in the hand of the sitting figure wearing the pig-tail, ${ }^{1}$ though there seems to be a flower with a long depending and somewhat fibrous root. The two objects apparently are presented in comparison or competition, while that in the hand of the standing figure has the superiority.

On the second face a very curious scene is depicted. Above a kind of altar in the centre is a trident-like object, evidently identical with that already described. The trident-like object is between two symbols of remarkable form, capped with equilateral triangles. On these remarkable symbols, which probably represent life in general, or particularly human life, something more must be said directly. A figure, probably that of a deity, with the head of a hawk or eagle, ${ }^{2}$ is pouring out a libation at the foot

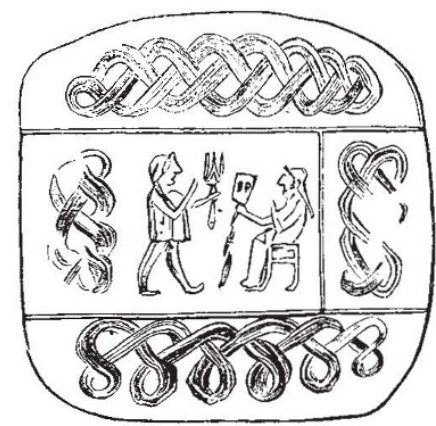

I
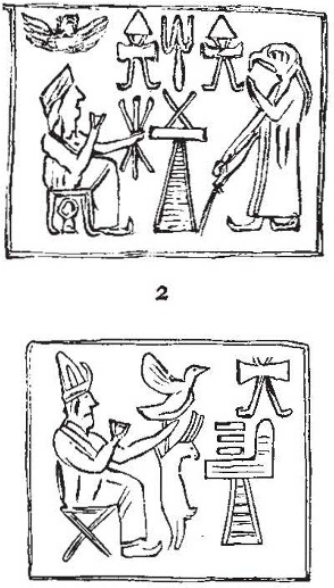

4

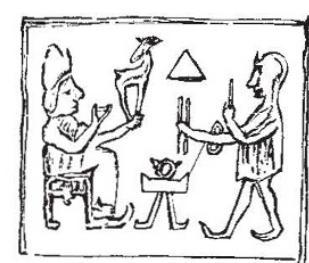

3

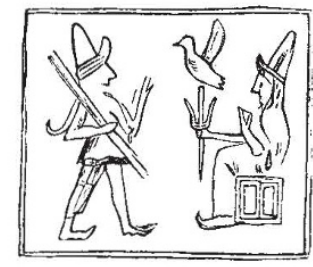

5
Fic. V.-The Tarsus seal (enlarged).

of the altar, and thus, we may presume, is confessing the superiority of the sacred objects above. On the other side of the altar is, it may be supposed, another deity, having above his head the winged solar disk, and in his left hand a double three-forked thunderbolt, introduced here, it may be supposed, as another emblem of tri-unity.

On the third face there is no personage wearing the

"Prof. Sayce has rightly recognized the presence of the "pig-tail," but when he says that this appendage "characterizes Hittite female figures" (op. cit. p. 348), I fail to see any adequate grounds for the assertion. This I should say, is not the mode of wearing the hair seen on the Boghaz-Keu bas-relief; and I am not acquainted with other evidence which would in any way justify the statement.

The form of this deity suggests a possible relation with the eagle-headed deity on the Assyrian monuments, concerning which Assyriologists have been hitherto unable to give any adequate explanation. Perhaps soine fresh light may be eventually derived from the "pig-tail" here appended. pig-tail. Both the seated and the standing figures appear to be occupied with the mystery of the triangle. The engraver of the seal, moreover, as though determined that we should not mistake his meaning, actually represents the seated figure as forming a triangle with one hand. On face (4) the triangle formed by the hand is particularly clear in the impression of the seal ; but there can scarcely be a doubt that the intention is the same also on this face (3) as well as on (2) and (5). How the triangle is supposed to be formed by the hand I am unable to say. By comparing the two hands of the seated figure in (3) it becomes evident that the goat standing on the left hand is here introduced as forming a triangle by his position. But still more remarkable and interesting is the personage standing, if considered together with the associated objects. This personage is supporting, apparently by a cord, a figure similar to those spoken of in connection with the second face as probably representing life in general, or more particularly the principle of human life. From the circular head of the figure are projecting what look like ears, but the triangular cap with which the head is covered on the second face is now seen above. The personage supporting the figure has in his left hand one rod held vertically, and in the right two vertical and parallel rods, thus suggesting the triangular number, three, a number regarded in antiquity as especially sacred.

The fourth face presents a single seated figure, making, as said just above, a triangle with the right hand. The left hand holds captive a hare as well as a bird with wings extended. The intention would seem to be to set forth the subjugation of the lower animals through the influence of such supposed occult and mysterious powers as those of the triangle. In front is an altar or table with objects upon it, which, it should be observed, are three in number. Above is a symbol generally identical with those spoken of in connection with faces (2) and (3), but here it is imperfect.

On the last face (5) we have apparently a competition between a pig-tailed figure standing or advancing and another figure seated. The pig-tailed figure holds two parallel rods or spears; and it would certainly appear that he is to be regarded as unequal in power to the seated figure, who is making a triangle with the left hand, while in the right hand is that symbol of tri-unity, the trident, now of more usual form, and differing considerably from the trident-like objects of (I) and (2). On the middle point of the trident is a bird with wings expanded. In this last respect the intention would seem to be somewhat similar to that expressed by the hare and bird held captive on face (4).

'The Tarsus seal is probably less ancient than the Yuzgât seal ; but there are nevertheless important points of resemblance, which may be reasonably taken as indicating a relationship more or less close. On both seals are to be seen the triangle and the trident, though on the Tarsus seal the form of the latter has become greatly changed. Both seals, also, have the winged solar disk. The wearing a horn in front of the head is another mark of resemblance ; and the figures on both seals have the turned-up toes of the so-called "Hittite boots." The eagle-headed figure making the libation has a good deal of similarity to what, as depicted on the Yuzgât seal, I regard as a woman closely veiled, with some object, probably a baby, suspended from her arm (supra, p. 560). Notwithstanding any superficial resemblance, however, the objects delineated are certainly very different. The explanation probably is, that the respective engravers had in view a common typical form, which was in each case modified as the particular purpose required. A similar remark may be made with respect to the table or altar on (4), and the object before the king on the Yuzgât seal.

Whether the Tarsus seal will be found of importance with regard to the history of geometry, it would be difficult to say. This may to some extent depend on the date 
to which the seal is to be referred. But, whatever may be the case with respect to the general history of geometry, certainly there are indications of something very like Pythagoreanism, such as we should by no means have expected to find on a Hittite or Asiatic monument. Still, however unexpected these indications may be, the scientific spirit requires that we should be loyal to facts. Among such indications may perhaps be placed the mysterious powers or properties apparently associated with vegetable forms on the Tarsus seal, as also on the Boghaz-Keui sculpture. But still greater importance and interest attach to the evidence of the seal as to the attribution of occult significance to number and to geometrical form. By the vertical rods of face (3) we are reminded of the Pythagorean doctrine concerning duality and unity, the even and the odd. (Plutarch, De Is. 48.) Moreover, we can scarcely mistake the sinister character of duality when we observe that the two parallel rods are carried on face (5) by the pig-tailed figure. Very probably the indications on the seal point to one of the sources whence were derived the doctrines attributed to Pythagoras. And such a view accords very well with the ancient tradition concerning the travels of Pythagoras, and the composite nature of Pythagoreanism.

But some additional consideration requires to be given to the figure on the Tarsus seal (faces 2, 3, 4), which I have spoken of as a symbol of life. In investigating the significance of this figure the most convenient method may be to compare it with the symbol most nearly resembling it which can be found elsewhere. This is to be seen on the coinage of Cyprus (Fig. W, 2). Here we have
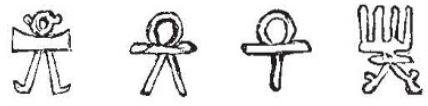

I

4
2

3
Fig. W.-1, Symbsl on Tarsus seal: 2, symbol on Cypriote coinage 3 , crux ansata; 4, symbol cn Indo-Scythian coin.

the rounded head (though without the projections on the symbol of the Tarsus seal), the horizontal stroke or body, and the divergent legs. True, on the seal there are slight projections at the ends of the horizontal piece, and at the ends of the divergent legs there are the "Hittite boots"; but in this last particular the symbol on the seal resembles the mandrake at Boghaz-Keui (supra, p. 5I4), the ends of the root being similarly turned up and metamorphosed. ${ }^{1}$ As to the meaning of the symbol on the Cypriote coinage, we can make a reasonable inference from the fact that it seems to be introduced as an alternative symbol in place of the crux ansata, or symbol of life, which, indeed, is quite common on Cypriote coins. ${ }^{2}$ The crux ansata was possibly derived from Egypt, but still it may very well be regarded as giving an indication of the meaning of the other symbol. If, however, the divergent legs of (2) are supposed to collapse, we have at once a crux ansata (3). The evidence so far would go towards the conclusion that the symbol on the Tarsus seal is a symbol of life. But by tracing the Cypriote symbol to its probable origin the evidence may be greatly strengthened.

The coins on which the Cypriote symbol just alluded to occurs are Phœnician. Now there occurs on Phœenician, and especially on Carthaginian, monuments a symbol by which scholars have been much puzzled. It consists of a triangle, normally, as it would seem, equilateral, though varying at times a good deal from this form. At the

1 The triangular cap of the symbol on face (2) shows a connection between the symbol and the equilateral triangle. But what may be exactly the differrence in the significance of the symbol when capped with the triangle and when destitute of this covering it is scarcely possible to say, unless the

added triangle is supposed to give power and vitality.
2 See De Vogué, "Mélanges d'Archéol gie Orientale," plate xi., Figs. $13,16,17,1^{2}$. vertex of the triangle is a horizontal stroke or bar, with projections at the ends, which may be taken for arms, or hands held up; and these also are found to present variations. Above is a head of circular form. This frequently occurring symbol, ${ }^{1}$ which may be seen to the reader's left in Fig. X, some scholars have taken for a representation of a man or woman praying and holding up his or her hands. But $M$. Renan justly observes that the position in which the symbol is found on the monuments is not compatible with such an opinion; and in the figure it evidently appears as

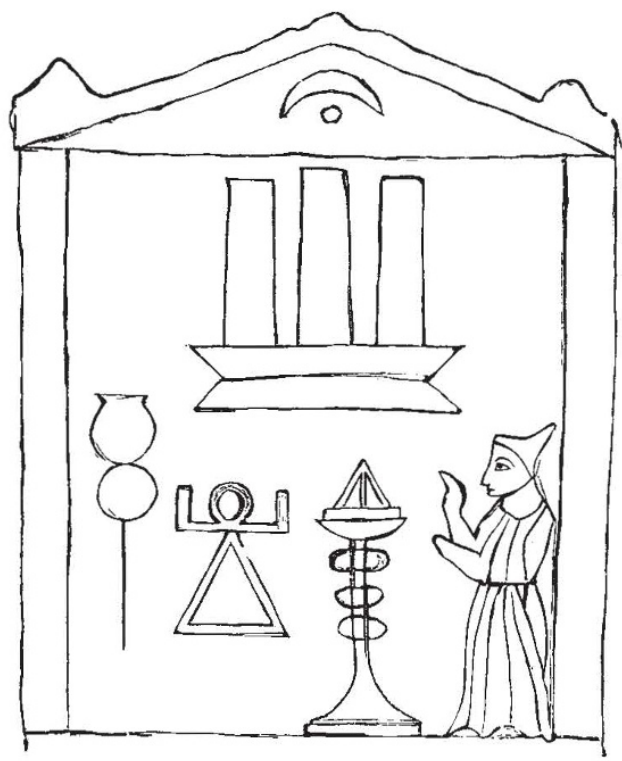

FIG. X.-Upper fortion of stele of Lilybæum.

an object of worship. Regarded as denoting life, or as a sort of generalization of deity as the giver of life, its position on the stele becomes intelligible. It corresponds in form with the Cypriote symbol, except that the latter has lost the base of the triangle and the projections at the end of the horizontal piece, but indications of these being retained are clearly to be seen on the Tarsus symbol. M. Renan could make nothing of the triple object above the altar in Fig. X. ${ }^{2}$ But when we look at the trident-like object of worship above the altar on face (2) of the Tarsus seal, the problem receives a good deal of light; and we recognize in the mysterious tripartite object of the stele a rnodification of the trident, expressing, like the triangle, the idea of tri-unity.

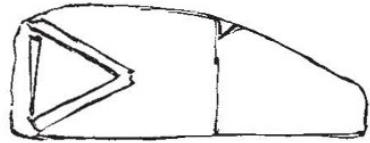

I

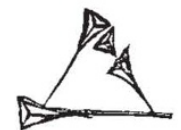

2
FIG. Y.- I, Portion of broken tablet in the British Museum ; 2, archaic cuneiform character, din, "life."

With respect to the loss of the base of the triangle in the Cypriote symbol, and the import of this and other symbols before mentioned, we have evidence on a unique tablet in the British Museum. Though it is unfortunately broken, its testimony is still very important. The tablet

$x$ M. Renan cbserves of this symbol: "Præcipua inter figuras religiosas est imago quâ nihil apud Phœenicas et Pœnos frequentius" ("Corp. inscr. sém.," vol. i. p. 28r).

${ }^{2}$ He observes: "Supra figura cernitur tripartita, tribus cippis imparibus constans, cum basi duplici, quæ quid sibi velit non apparet" (op. cit. vol. i. p. 179). Fig. X. is a little reduced from the figure in the "Corpus." 
gave the ancient hieroglyphic or hieratic forms of some cuneiform characters, with their values. Among these is a triangle the sides of which are represented by doubled lines carefully finished off, while the base, which is to a certain extent dissevered, is represented only by a single line or wedge. We thus see a tendency already to that dropping of the base exemplified in the Cypriote symbol. But is the meaning the same? The cuneiform character giving the value is unfortunately gone, except a small portion of a single wedge, which alone would yield but slender grounds for determining the import of the triangle. We are able, however, to take, together with the small portion of the wedge, the archaic cuneiform character denoting "life," and still retaining the semblance of an equilateral triangle. The value of "life" was that assigned to the triangle as it appears on the broken tablet, by M. Menant ; and Mr. Pinches, of the British Museum, is also of opinion that the fragment of the wedge remaining is entirely in accordance with this view.

Whence the idea originated that the primordial source of life was of triangular form, it is of course impossible to say. This was, however, an idea which prevailed very widely indeed in the East. A distinguished scholar and archæologist has directed my attention to symbols found on Indo-Scythian coins as being analogous to the Hittite and Cypriote symbols (see Fig. V, 4). It is not difficult to discern the two sides of the triangle and the horizontal stroke or bar. Instead, however, of the circular or rounded head, there are four vertical strokes, which there can be little difficulty in recognizing as a symbol of fire, a symbol which, in the case of Zoroastrians and fireworshippers, would be entirely suitable.

In connecting the Hittite symbol of the Tarsus seal with the Babylonian hieroglyphic triangle, we have gone back to an antiquity very remote indeed. But if we are to regard the symbols already discussed as connected also with the well-known Egyptian symbol of life, the $a n k h$, and with other Egyptian symbolic forms, our demand on time must probably be much greater. That the Egyptian talismans (Fig. $Z, 2,3,4$ ) might have been evolved from

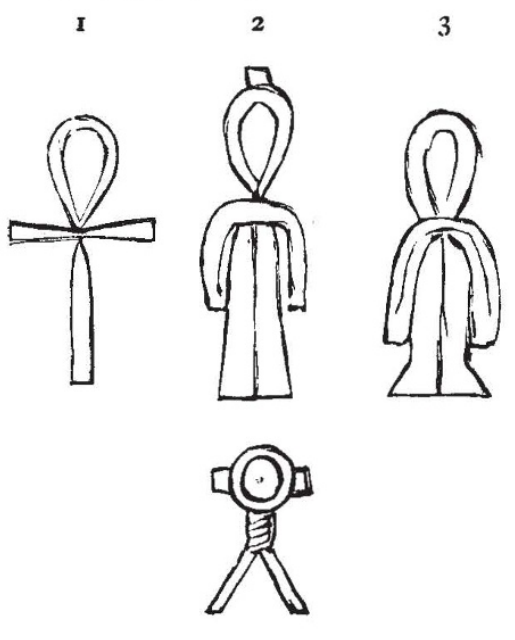

4

FIG. Z-x, Ankh, Egyptian symbol of life, from cuffin of Men-ka-ra, in the British Museum ; 2, 3, 4, Egyptian talismans in the British Museum.

a form identical with, or resembling, the headed triangle of the Phœnician monuments, it requires no great stretch of imaginative power to discern. ${ }^{1}$ But with regard to the $\operatorname{ankh}(\mathrm{I})$, so often seen in the hands of deities, though the

${ }^{x}$ The distinguished Egyptologis', Mr. Le Page Renouf, now Keeper of Oriental Antiquities at the British Museum, tells me that, while (2) and (3) may not be earlier than the eighteenth dynasty, (4) is of very great antiquity, occurring in the name of Hor-em-sa-f, one of the Pyramid kings. points of resemblance are tolerably obvious, ${ }^{1}$ yet it may seem difficult to understand how the triangle could have assumed the form of the vertical bar. True, the bar is pointed at the apex; and elsewhere on the Egyptian monuments an acute-angled triangle in the corresponding position is sufficiently common. But it is remarkable that this latter form is not seen on a monument so very ancient as the coffin of the king Men-ka-ra. Still, on the whole, it can scarcely be regarded as other than probable that the ankh, like the other. Egyptian forms depicted, must be referred ultimately to the headed triangle. But, if this view is just, and the triangle had collapsed, as shown in the figure, when the coffin of Men-ka-ra was constructed, the period of man's existence on the earth in a condition of somewhat advanced civilization must be of exceedingly protracted duration.

As to the age of the greater Hittite monuments, it is impossible to speak. To argue that the Hittite hieroglyphs could not have remained long in use by the side of either the cuneiform syllabary or the Phœnician alphabet would be somewhat perilous. A better argument for their great antiquity is furnished by the total absence, so far as can be seen, of any indication of horses or chariots. Yet, in the wars with the Egyptians some fifteen or sixteen centuries before Christ, the Hittites appear well equipped with this kind of forces, in a state of organization from which lengthened usage may be reasonably inferred.

What has been said may suffice to show the extremely great interest of the questions suggested by the Hittite monuments. Unfortunately the material for investigation is at present but scanty, though there are probably hundreds, perhaps thousands, of monuments awaiting the spade of the excavator. The very important results obtained by the British Museum from the excavations at Jerablûs have not prevented these excavations from being for a considerable time wholly suspended. That this should be the case is certainly matter for regret; for I hope that $\mathrm{I}$ have at least succeeded in showing that the idea that the solution of the Hittite problem is hopeless is one which cannot be reasonably entertained.

\section{CLASS EXPERIMENTS.}

T $\mathrm{HE}$ following is a brief account of some experiments shown to the students of the Natural Philosophy Class in the University of Glasgow during the present Session. It is communicated to NATURE with the permission of Sir W. Thomson.

I. (I) Suspend a heavy ball by a long wire, as shown in Fig. I. To the middle of the ball attach a worsted thread, A.D. Pull the thread in the direction of the arrow-head, with a pull that will not break it, and let the pull be finished before the ball is sensibly displaced. Observe the greatest subsequent displacement of the ball.

(2) Bring the ball to rest. Pull it now with a pull sufficient to break the thread. Note that the displacement is smaller than in case ( $\mathrm{I}$ ).

(3) Bring the ball to rest once more. Give a very sudden pull to the thread: it breaks, and the displacement of the ball is hardly perceptible.

In each of the three cases the momentum is equal to $\int \mathrm{F} d t$ for the whole duration of the pull. The pull in case ( 1 ) is smaller than the pull in cases (2) and (3), but the duration of the pull is greater in a greater ratio; hence the momentum communicated, being the time integral of the pull, is the greatest for case (I). Although the pull in case (2) is equal to the pull in case (3), still its

$x$ The connection with, or analogy between, the Tarsus and Cypriote symbols and the ankh was suggested by Mr. Pinches, and subsequently, with respect to the Tarsus symbol, on different grounds, by Prof. Sayce. 